\title{
Effectiveness of Group Schema Therapy in Reducing the Symptoms of Major Depression in a Sample of Women
}

\author{
Roghayeh Hashemi ${ }^{1} \&$ Kobra Darvishzadeh ${ }^{2}$ \\ 1. Department of Psychology, Qeshm International Branch, Islamic Azad University, Qeshm, Iran \\ 2. Department of Psychology, Islamic Azad University, Ahvaz Branch, Ahvaz, Iran \\ Correspondence: Kobra Darvishzadeh, Department of Psychology, Islamic Azad University, Ahvaz Branch, \\ Ahvaz, Iran. Postal Code: 61349-37333. Tel: 98-61-1334-8420. E-mail: mdarvishzadeh@yahoo.com
}

\author{
Received: April 16, 2016 Accepted: April 22, 2016 Online Published: May 20, 2016 \\ doi:10.5539/ass.v12n6p232 URL: http://dx.doi.org/10.5539/ass.v12n6p232
}

\begin{abstract}
Treatment of the symptoms of major depression is one of the important issues in the treatment of psychological disorders. This study aims to investigate effectiveness of group schema therapy in reducing the symptoms of major depression in a sample of women in the Ahvaz City. This is a quasi-experimental with two control and treatment groups. To this end, 30 married women in Ahvaz were selected using the convenience sampling method and were included in two treatment and control groups of 15 persons. After pre-test for both groups, the experimental group received schema therapy in 10 sessions for one month; however, the control group received no training. Beck Depression Inventory that has an acceptable reliability and validity was used to assess depression. Finally, test scores were analyzed by analysis of covariance. The results showed that group schema therapy training was effective at the level of error $\mathrm{P}<0.0001$ on reducing the symptoms of depression in the treatment group. Accordingly, it can be concluded that the group schema therapy training affects the mental health promotion. Therefore, the intervention can be effective in preventing mental injuries.
\end{abstract}

Keywords: group schema therapy training, major depression, mental health

\section{Introduction}

All people may experience depression in different stages of their lives. It can affect their physical, emotional, behavioral, and mental health. Symptoms such as sadness, feelings of worthlessness, difficulty in concentrating, inability to think, a sense of guilt, insomnia, feelings of failure and many other dangerous symptoms can be observed in depressed people (Amami, 2003). Depression is one of the most common mental disorders. Depression is one of the most important types of mood disorders and its lifetime prevalence is 15 percent (Angst et al., 2009). The main features of depression include a period of at least two weeks of depressed mood, loss of interest or lack of joy. Moreover, The person must have at least a few other symptoms including changes in appetite or weight, sleep and psychomotor tasks, reducing power, feelings of worthlessness or guilt, difficulty in thinking, decentralization in decision-making, recurrent thoughts of death and suicide, planning or attempt for suicide (Imel et al., 2008). Depression is a common disease in the world with the debilitating effect (Lopez et al., 2006). Although depression is largely treatable, but about 20 percent of people with major depression may experience chronic depression (Gilmer et al., 2005).

The average age of depression is 20 years old with depression and if is associated with suicide or hospitalization, it may be likened to the non-chronic depression (Satyanarayana et al., 2009). Schema therapy approach focuses on early maladaptive schemas (Young, Klosko, \& Weishaar, 2003) and includes the permanent beliefs and patterns that have been formed in childhood and adolescence and are developed in adulthood. These beliefs show high resistance to the changes because people view the world relying on these beliefs. Therefore, it seems that the new schema therapy approach with an emphasis on early maladaptive schemas of the childhood and adolescence can be useful in the treatment of depression. The results of the studies on depression show that the early maladaptive schemas are one of the important predictors of depression during treatment (Halvorsen et al., 2010) and after 9 years of follow-up (Renner et al., 2012).

Young believes that early maladaptive schemas is one of the oldest cognitive components and beliefs and non-conditional emotions about ourselves and are resulted from mood interaction with the inefficient 
experiences with parents, family members, and peers in childhood and these non-conditional schemas increases the vulnerability and neurotic disorders and psychological problems increases (Young, 1994). They are selfcontinuous patterns of memories, emotions, cognition, senses, and human perception of the environment. They act easily based on the habits and when the person encounter the challenges, they distort the received information instead of changing the schema (Young, Klosko, \& Weishaar, 2003). Studies have shown that early maladaptive schemas are characterized by various symptoms. For example, perfectionism schema is characterized by symptoms of anxiety and depression (Gilmer et al., 2005) and psychological incompatibility (Young, Klosko, \& Weishaar, 2003) and eating disorders, psychosomatic symptoms, anxiety and job depression, and so on (Kamali et al., 2011).

Theorists of schema therapy criticize cognitive methods, cognitive -behavioral therapy methods, and other methods and believe that their solution is proper to reduce symptoms of anxiety and depression. In this approach, schema therapy includes the same patterns or comprehensive themes that are composed of memories, emotions, cognitions, and physical emotions, and they are formed in childhood or adolescence and are continued forever (Young, Klosko \& Weishaar, 2003). Schema therapy is a new and integrated treatment that provides a systematic program for evaluating and modifying the early maladaptive schemas. It is based on the classic cognitive-behavioral therapy and combines interpersonal, attachment and experimental cognitive-behavioral techniques for measuring and modifying of early maladaptive schemas. Schema therapies focus on the development origins of the psychological problems in childhood, adolescence, and the use of driving techniques and providing the concept of the maladaptive coping styles (Young, 2001). Young believes that since schema therapy focuses on the deepest level of cognition, it aims to modify the core problem and this substantially decreases the symptoms of anxiety, depression, and its return (Pinto-Gouveia et al., 2006).

The results suggest the effectiveness of schema therapy in improving the symptoms of anxiety (Hamidpoor, 2000) and depression (Zerehpoosh, 2011). For example, in discussing the effectiveness of schema therapy in improving the anxiety, Capron et al. concluded that schema therapy reduces anxiety sensitivity (Capron, Kotov, \& Schmidt, 2013). Concerning the effectiveness of schema therapy in improving the depression, Reiner et al. in their study on early maladaptive schemas in depressed patients concluded that maladaptive schemas lead to the depression and schema therapy can be used in the treatment of depression (Renner, 2012).

Hosseini et al. (2011) concluded that schema therapy significantly reduced depression symptoms in the treatment group. Parizadeh (2011) investigated and compared the effectiveness of the existential group therapy and group reality therapy in depression, anxiety, stress, and solving the body-image problem in women and found that existential group therapy and group reality therapy equally decrease emotional disorders. Zerehpoush (2011) in a study entitled effectiveness of the schema therapy in chronic depression in students concluded that schema therapy significantly reduces the symptoms of chronic depression. Hashemi et al. (2010) investigated the effectiveness of meta-cognitive therapy in depression and concluded that the meta-cognitive therapy leads to a significant decrease in depression in the treatment group.

Gharaei (2004) investigated the effect of cognitive and metacognitive models on patients suffering from anxiety and depression and concluded that in the post-test, cognitive model significantly reduce anxiety and depression. Askari (2012) studied the effectiveness of the group schema therapy and group reality therapy in reducing the return and increasing the general health of the addicts and found that both models increase the general health and decrease the disease return. Malekpour (2012) evaluated the effectiveness of schema therapy in depression, dysfunctional attitudes, and negative automatic thoughts of the students and concluded that group schema therapy can significantly reduce depression, negative automatic thoughts, and dysfunctional attitudes in the treatment group.

Montazeri et al. (2013) in a study entitled effectiveness of schema therapy in reducing the severity of symptoms of depression and obsessive-compulsive personality disorder concluded that schema therapy reduces symptoms of depression and obsessive-compulsive personality in patients with obsessive-compulsive personality disorder. Yousefi (2011) in a study entitled the effectiveness of meaning therapy and Gestalt therapy in reducing symptoms of depression, anxiety and hostility among the divorce-seeking women of Saghez City and found that these approaches are effective in reducing symptoms of depression, anxiety and hostility. Zolfaghari and Fatehizadeh (2008) in a study entitled the effectiveness of schema therapy on marital attributions and communicative beliefs concluded that schema therapy improves the marital communicative attributions and communicative beliefs.

Hamidpour (2011) in a study entitled the preliminary study on the efficiency and effectiveness of schema therapy in the treatment of love failures found that that schema therapy leads to the significant changes in the rates of 
depression, self-esteem and improves the five maladaptive schemas (emotional deprivation, abandonment, mistrust / abuse, defeat and enmeshment/ undeveloped self. Mokhtari et al. (2009) in a study entitled effectiveness of schema therapy in marital satisfaction of married people with personality disorder and obsessive-compulsive personality disorder found that schema therapy reduces symptoms of obsessive-compulsive personality disorder of the married people. Hamidpour (2011) in his study entitled the effectiveness of the schema therapy in the treatment of women with generalized anxiety disorder concluded that schema therapy is effective in the treatment of generalized anxiety disorder of the women. Kameli et al. (2011) investigated the effectiveness of the cognitive group therapy based on the schemas in modifying the early maladaptive schemas in adolescent girls with uncaring and mal-caring parents and concluded that cognitive group therapy based on the schemas significantly decrease the total score of the questionnaire of the early maladaptive schemas of Young. Dehkhoda (2012) in his study entitled effectiveness of the spirituality-based cognitive therapy in reducing the depression symptoms of the mothers with cancer found that spirituality-based cognitive therapy can reduce the depression symptoms and promotes the spiritual experience. Given the importance of the role of schemas in mental diseases and the importance of these diseases among women and men, this study aimed to evaluate the effectiveness of group schema therapy in reducing symptoms of major depression in a sample of women.

\section{Methods}

\subsection{Population, Sample, and Sampling Method}

This is a classic quasi-experimental study with a control group. For the aim of the study, 30 women with symptoms of major depression were selected by Ahvaz experts using the available sampling method and purposive approach in 2014 and after investigating the mean homogeneity of the scores of each scale, they are divided into two treatment and control groups of 15 persons. The treatment group received training in 10 sessions of 90 minutes over a period of 60 days by two senior experts of the family counseling and clinical psychology. However, the control group received no training. After the sessions, two groups were re-tested (post-test). Inclusion criteria are as follows: age between 20 to 50 years old, individual informed consent to participate in this study, ability to read and write, participant's commitment in order not to leave the training sessions during the period. The content of the training are based on the solution-based perspective and this content has been used in the previous periods. Experts and scholars' ideas were used for re-analyzing the content of this training period and finally, this content was trained.

First session: explaining the schema model in a simple, clear language, the ways the early maladaptive schemas were formed, developmental roots, and its areas, functions of schema, styles, and maladaptive coping responses.

Second session: training the schemas, conceptualizing of the problems of the patients based on the schema-based approach and collecting all the information obtained during the assessment, identifying disturbed areas of schema of patients, investigating the objective evidences confirming and rejecting the schemas based on the evidence of the patient's past and current life.

Third session: teaching two cognitive schema therapy techniques, including tests of schema validation and the new definition of supporting evidence.

Fourth session: teaching and practicing two other cognitive techniques, evaluating the advantages and disadvantages of coping styles of the patients, contacting between the different aspects of schema and healthy aspects and learning answers of healthy aspects by the patient (Safarinia et al., 2014).

Fifth session: teaching techniques to provide training cards of the schemas, writing schema registration form during daily life.

Sixth session: offering rationale for using the experimental techniques, mental imagery, mental image conceptualization in the form of an imaginary dialogue, strengthening the concept of healthy adult in patient's mind, identifying unsatisfied emotional needs, and fighting against the schema in an emotional level.

Seventh session: creating opportunities for patients to communicate with parents and identify their needs unsatisfied by parents, helping the patient to express the blocked emotions on the traumatic event and providing the patient support.

Eighth Session: finding new ways to communicate and giving up the avoidant and excessive compensatory coping style, providing a comprehensive list of the problematic behaviors, determining the change priorities and identifying the therapeutic targets.

Ninth session: mental imagery of the problematic situations and dealing with the most problematic behavior, 
practicing the healthy behaviors through imagery and playing role and performing tasks related to new behavioral pattern, reviewing the advantages and disadvantages of the healthy and unhealthy behaviors.

Tenth session: Overcoming barriers of the behavioral changes, summary, and conclusion (Safarinia et al., 2014).

\subsection{Research Instruments}

Beck Depression Inventory Short Form (BDI-13): Beck Depression Inventory consists of 13 self-reporting items that show the certain symptoms of depression. Each items is rated from zero to four and its maximum and minimum scores are arranged between 39 and zero, respectively. This scale was developed for various fields of depression semiology such as emotional, cognitive, motivational, and physiological depression (Rajabi, 2005). Hojat et al. (1986) found the positive correlations between Beck depression Inventory and the indices of anxiety, loneliness, and external control locus. They showed that Beck depression Inventory has necessary validity and reliability for Iranian students. Rajabi based on factor analysis identified two factors of negative affectivity towards self and pleasurelessness (52.54). He obtained Cronbach's alpha coefficient of the questionnaire as 0.89 and the simultaneous correlational coefficient as 0.67 using the BDI-21 form (Rajabi, 2005).

SPSS-22 was used for data analysis and results were reported in the form of descriptive and inferential statistics. In order to normalize the data for parametric tests, Kolmogorov - Smirnov one-sample was used. For comparing the pre-test and post-test means of the treatment and control groups, dependent T-test was used and finally, for comparing the significant differences in the treatment group compared to the control group, ANCOVA was used.

\section{Result}

Age range of the treatment group was $39.17 \pm 2.17$ and that of control group was $37.22 \pm 2.12$. The highest age of participants was 45 and the minimum age was 28 . In order to check the normality of the data, the Kolmogorov - Smirnov one-sample test was used. Results showed that research variables were not significant at the significance level of $\mathrm{P} \leq 0.05$. Therefore, distribution of the scores of variables is normal and parametric tests can be implemented. Results of Levine test in Table 1 also show that research groups are comparable with each other.

Table 1. The results of Levin test to evaluate the equality of the variances of the two groups

\begin{tabular}{ccccc}
\hline Variables & $\mathrm{F}$ & $\mathrm{df1}$ & $\mathrm{df2}$ & Sig. \\
\hline Depression & 1.384 & 1 & 28 & .249 \\
\hline
\end{tabular}

Table 2. Statistical Properties for Variables in the Pretest, Posttest on the Studied Groups

\begin{tabular}{cccccccc}
\hline Groups & & Mean & $\mathrm{N}$ & Std. Deviation & $\mathrm{t}$ & $\mathrm{df}$ & $\mathrm{P}$ \\
\hline \multirow{2}{*}{ Test } & Pre-test & 16.6000 & 15 & 4.93964 & \multirow{2}{*}{6.500} & \multirow{2}{*}{14} & .000 \\
& Post-test & 11.4000 & 15 & 4.23927 & & & \\
\multirow{2}{*}{ Control } & Pre-test & 17.2000 & 15 & 4.00357 & \multirow{2}{*}{1.581} & \multirow{2}{*}{14} & .136 \\
& Post-test & 16.5333 & 15 & 3.33524 & & \\
\hline
\end{tabular}

Dependent T-test results between control and treatment groups were reported in Table 2 in order to analyze and compare the means. The results show that the mean of treatment groups in pre-test and post-test is significantly different in terms of the symptoms of depression. However, there is no significant difference between means of the control group in pre-test and post-test. T-test results indicated that research groups are comparable with each other. Accordingly, foe analyzing the effectiveness of schema-focused therapy group, covariance analysis was used.

Table 3. Statistical Properties for Variables in the Pretest, Posttest on the Studied Groups

\begin{tabular}{ccccccc}
\hline Source & Type III Sum of Squares & df & Mean Square & F & Sig. & Partial Eta Squared \\
\hline Corrected Model & $481.451^{\mathrm{a}}$ & 2 & 240.725 & 52.621 & .000 & .796 \\
Intercept & 7.431 & 1 & 7.431 & 1.624 & .213 & .057 \\
Pre-test & 283.817 & 1 & 283.817 & 62.041 & .000 & .697 \\
group & 165.482 & 1 & 165.482 & 36.174 & .000 & .573 \\
Error & 123.516 & 27 & 4.575 & & & \\
Total & 6457.000 & 30 & & & & \\
Corrected Total & 604.967 & 29 & & & & \\
\hline
\end{tabular}


Results of covariance analysis showed there is a significant difference between experimental and control groups in terms of depression. Therefore, with respect to the significant difference of the means of research variables in treatment group, depression variable compared to the control group in Table 2 and significant difference resulting from the covariance test in Table 3 , it can be concluded that changes are resulted from the training interventions and independent variable. Moreover, Eta-square shows the impact factor of schema-focused group therapy in improving the symptoms of depression in the treatment group.

\section{Discussion and Conclusion}

This study aims to investigate effectiveness of group schema therapy in reducing the symptoms of major depression in a sample of women in the Ahvaz City. The results imply that the training of schema therapy group had an effect on reducing the symptoms of depression in the treatment group. Previous studies have also confirmed the effectiveness of schema therapy on reducing the depression and other mental diseases. The results suggest the effectiveness of schema therapy in improving the symptoms of anxiety (Hamidpoor, 2000) and depression (Zerehpoosh, 2011). For example, in discussing the effectiveness of schema therapy in improving the anxiety, Capron et al. concluded that schema therapy reduces anxiety sensitivity (Capron, Kotov \& Schmidt, 2013).

Concerning the effectiveness of schema therapy in improving the depression, Reiner et al. in their study on early maladaptive schemas in depressed patients concluded that maladaptive schemas lead to the depression and schema therapy can be used in the treatment of depression (Renner, 2012). Hosseini et al. (2011) concluded that schema therapy significantly reduced depression symptoms in the treatment group. Zerehpoush (2011) in a study entitled effectiveness of the schema therapy in chronic depression in students concluded that schema therapy significantly reduces the symptoms of chronic depression. Hashemi et al. (2010) investigated the effectiveness of meta-cognitive therapy in depression and concluded that the meta-cognitive therapy leads to a significant decrease in depression in the treatment group.

Askari (2012) studied the effectiveness of the group schema therapy and group reality therapy in reducing the return and increasing the general health of the addicts and found that both models increase the general health and decrease the disease return. Malekpour (2012) evaluated the effectiveness of schema therapy in depression, dysfunctional attitudes, and negative automatic thoughts of the students and concluded that group schema therapy can significantly reduce depression, negative automatic thoughts, and dysfunctional attitudes in the treatment group.

Montazeri et al. (2013) in a study entitled effectiveness of schema therapy in reducing the severity of symptoms of depression and obsessive-compulsive personality disorder concluded that schema therapy reduces symptoms of depression and obsessive-compulsive personality in patients with obsessive-compulsive personality disorder. Yousefi (2011) in a study entitled the effectiveness of meaning therapy and Gestalt therapy in reducing symptoms of depression, anxiety and hostility among the divorce-seeking women of Saghez City and found that these approaches are effective in reducing symptoms of depression, anxiety and hostility.

Zolfaghari and Fatehizadeh (2008) in a study entitled the effectiveness of schema therapy on marital attributions and communicative beliefs concluded that schema therapy improves the marital communicative attributions and communicative beliefs. Hamidpour (2010) in a study entitled the preliminary study on the efficiency and effectiveness of schema therapy in the treatment of love failures found that that schema therapy leads to the significant changes in the rates of depression, self-esteem and improves the five maladaptive schemas.

Mokhtari et al. (2009) in a study entitled effectiveness of schema therapy in marital satisfaction of married people with personality disorder and obsessive-compulsive personality disorder found that schema therapy reduces symptoms of obsessive-compulsive personality disorder of the married people. Hamidpour (2010) found that schema therapy is effective in the treatment of generalized anxiety disorder of the women. Kameli et al. (2011) showed that cognitive group therapy based on the schemas significantly decreases the total score of the questionnaire of the early maladaptive schemas of Young.

Therefore, it can be said that schema therapy approach consists of interpersonal, attachment and experimental cognitive-behavioral techniques in the form of an integrated treatment model. It is the basis of the inefficient and irrational thoughts and examines the maladaptive schemas using the four main techniques of cognitive-behavioral, communicative, and experimental in depressed and anxious people. Emotionally, it helps people to express their positive and buried negative emotions such as anger due to the lack of satisfying the spontaneous needs and secure attachment to others in childhood. In other words, schema therapy is effective in behavioral pattern breaking. This strategy helps to plan and implement for replacing the maladaptive coping responses by adaptive behavioral patterns. In addition, the main techniques of schema therapy play an important 
role in the success of this approach, such as cognitive technique for testing the accuracy of such schemes. To this end, some strategies such as schema validation new definition of the confirming evidence of schema, dialogue between the healthy aspect and schema aspect are used and in this way, referees can realizes there is a health voice in his mind in addition to the schema voice.

One of the schema therapy is focusing on the ineffective coping style of the patients that were formed in childhood and continued to adulthood. Studies show that changing the coping style in depressed people has been associated with reduction of the symptoms of depression (Schmaling et al., 2002). Schema therapy tries to change these styles using the techniques for changing the maladaptive schemas. There is no follow-up phase for the present study and this is one of the research limitations. Using a therapeutic approach in the treatment of depression and not using other approaches is of other limitations of this study. The study population included only women and this is another research limitation. Effectiveness of therapy approach should be investigated in follow-up study and additional tests should be in the study.

\section{References}

Amami, F. (2003). Prevalence of depression in students of medical sciences (Ph.D. Thesis). Ardebil University of Medical Sciences.

Angst, J., Gamma, A., Rössler, W., Ajdacic, V., \& Klein, D. N. (2009). Long-term depression versus episodic major depression: results from the prospective Zurich study of a community sample. Journal of affective disorders, 115(1), 112-121. http://dx.doi.org/10.1016/j.jad.2008.09.023

Asghari Jannat Abad, M. (2012). Check and compare the effectiveness of Schema therapy and reality therapy in reducing relapse rates and enhance public health. Master degree. Clinical Psychology Birjand.

Capron, D. W., Kotov, R., \& Schmidt, N. B. (2013). A cross-cultural replication of an interactive model of anxiety sensitivity relevant to suicide. Psychiatry research, 205(1), 74-78. http://dx.doi.org/10.1037/a0036651

Dehkhoda, A. (2012). The effectiveness of cognitive therapy in reducing depressive symptoms in mothers of children with cancer centered spirituality (Master thesis). Counseling Psychology. University of Social Welfare and Rehabilitation.

Gharaee, B. (2004). Consideration some of cognitive and met cognitive models in patients with anxiety and depression. Tehran: Tehran Psychiatric Institute.

Gilmer, W. S., Trivedi, M. H., Rush, A. J., Wisniewski, S. R., Luther, J., Howland, R. H., \& Alpert, J. (2005). Factors associated with chronic depressive episodes: a preliminary report from the STAR-D project. Acta Psychiatrica Scandinavica, 112(6), 425-433. http://dx.doi.org/10.1111/j.1600-0447.2005.00633.x

Halvorsen, M., Wang, C. E., Eisemann, M., \& Waterloo, K. (2010). Dysfunctional attitudes and early maladaptive schemas as predictors of depression: A 9-year follow-up study. Cognitive Therapy and Research, 34(4), 368-379. http://dx.doi.org/10.1007/s10608-009-9259-5

Hamidpoor, H. (2009). A preliminary study on the efficiency and effectiveness of schema therapy the students love failure. The fourth seminar on mental health of students in Shiraz, 91-93.

Hamidpour, H., Dolatshai, B., Pour Shahbaz, A., \& Dadkhah, A. (2011). The Efficacy of Schema Therapy in Treating Women's Generalized Anxiety Disorder. J Psych Clin Psycho, 16(4), 420-31.

Hashemi, Z., Mahmood Alilou, M., \& Hashemi Nosrat Abadi, T. (2010). Efficacy of met cognitive treatment in major depression: case study. J Clin Psycho, 7(3), 85-97.

Hojat, H., Shapurian, R., \& Mehryar, A. H. (1986). Psychometric Properties of a Persian Version of the Short Form of the Beck Depression Inventory for Iranian College Students, Psychological Reports, 59, 331-338.

Hoseini, N., Razavi Nemattollahi, V., Hosinifard, S. M., \& Hasannejad, B. (2011). The effectiveness of schema therapy on women with depression. $J$ Wom \& Stu of Fam, 3(12), 49-64.

Imel, Z. E., Malterer, M. B., McKay, K. M., \& Wampold, B. E. (2008). A meta-analysis of psychotherapy and medication in unipolar depression and dysthymia. Journal of affective disorders, 110(3), 197-206. http://dx.doi.org/10.1016/j.jad.2008.03.018

Lopez, A. D., Mathers, C. D., Ezzati, M., Jamison, D. T., \& Murray, C. J. (2006). Global and regional burden of disease and risk factors, 2001: systematic analysis of population health data. The Lancet, 367(9524), 1747-1757. http://dx.doi.org/10.1016/S0140-6736(06)68770-9 
Malek Pour dehkordi, A. (2012). Evaluation of the effectiveness of schema therapy on depression, dysfunctional attitudes and negative automatic thoughts in students (Master thesis). General Psychology. Tehran.

Mokhtari, S., Bahrami, F., \& Pvrshhryary, M. S. (2009). Effectiveness of schema therapy on marital satisfaction of married individuals with obsessive-compulsive personality disorder (Master's thesis). Counseling Psychology. Al-Zahra University.

Montazeri, M., Neshatdoost, H., Abedi, M., \& Abedi, A. (2013). Effectiveness of Schema Therapy on Symptoms Intensify Reduction and Depression in a Patient with Obsessive Compulsive Personality Disorder: A Single Case Study. Journal of Clinical Psycology, 5(1), 35-45.

Parizadeh, H. (2012). Review and compare the effectiveness of group therapy and reality therapy on depression, anxiety, stress and problem solving Tastktvmy the image of women (Master's thesis). Clinical psychology. Mashhad Ferdowsi University.

Pinto-Gouveia, J., Castilho, P., Galhardo, A., \& Cunha, M. (2006). Early maladaptive schemas and social phobia. Cognitive Therapy and Research, 30(5), 571-584. http://dx.doi.org/10.1007/s10608-006-9027-8

Rajabi, Gh. (2005). Psychometric Characteristics of Psychometric Properties of Beck Depression Inventory Short Form Items (BDI-13). Journal of Iran Psychologist, 4(3), 291-298.

Renner, F., Lobbestael, J., Peeters, F., Arntz, A., \& Huibers, M. (2012). Early maladaptive schemas in depressed patients: Stability and relation with depressive symptoms over the course of treatment. Journal of affective disorders, 136(3), 581-590. http://dx.doi.org/10.1016/j.jad.2011.10.027

Renner, F., Lobbestael, J., Peeters, F., Arntz, A., \& Huibers, M. (2012). Early maladaptive schemas in depressed patients: Stability and relation with depressive symptoms over the course of treatment. Journal of affective disorders, 136(3), 581-590. http://dx.doi.org/10.1016/j.jad.2011.10.027

Saffarinia, M., Zare, H., Karami, J., \& Solgi, Z. (2014). The efficacy and continuing impact of group schema therapy in treating students' social anxiety disorder. Pajoohandeh Journal, 19(4), 211-218.

Satyanarayana, S., Enns, M. W., Cox, B. J., \& Sareen, J. Prevalence and correlates of chronic depression in the Canadian community health survey: mental health and well-being. Can J Psychiatry, 54(6), 389-98.

Young, J. E. (1994). Cognitive therapy for personality disorders: A Schema focused approach. Sorasota, Professional resource press.

Young, J. E. (2001). Young Parenting Inventory. New York: Cognitive Therapy Center of New York; 2001.

Young, J. E., Klosko, J. S., \& Weishaar, M. E. (2003). Schema Therapy: A Practioner's Guide. New York, NY: Guilford Press.

Yousefi, N. (2011). Comparison of the Effectiveness of Family Therapy Based on Schema Therapy and Bowen's Emotional System Therapy on Divorce Tendency Among Divorce Applicant Clients. Journal of Clinical Psychology, 3(3), 53-64.

Zerehpoosh, A. (2011). The effectiveness of schema therapy on chronic depression in Isfahan University students. Isfahan: Isfahan University.

Zolphaghari, M., \& Fatehizadeh, M. S. (2008). Schema therapy effect on marital and relationship beliefs in city documents (Master's thesis). Family Counseling. Isfahan.

\section{Copyrights}

Copyright for this article is retained by the author(s), with first publication rights granted to the journal.

This is an open-access article distributed under the terms and conditions of the Creative Commons Attribution license (http://creativecommons.org/licenses/by/3.0/). 